\title{
Clinical Significance of Urinary Tract Infection among Newborns with Hyperbilirubinemia
}

\author{
Erhan Aygün ${ }^{1 *}$, Sinan Tüfekci ${ }^{2}$ \\ ${ }^{1}$ Department of Pediatrics, Istanbul School of Medicine, Istanbul University, Turkey \\ ${ }^{2}$ Department of Pediatrics, Tekirdağ Namık Kemal University, Turkey
}

*Corresponding author: Erhan Aygün, Division of Neonatology, Department of Pediatrics, Istanbul School of Medicine, Istanbul University, 34093 Istanbul, Turkey.

To Cite This Article: Erhan Aygün, Clinical Significance of Urinary Tract Infection among Newborns with Hyperbilirubinemia. 2020 - 9(6). AJBSR. MS.ID.001459. DOI: 10.34297/AJBSR.2020.09.001459.

Received: 眥July 16, 2020; Published: 制 August 17, 2020

\begin{abstract}
Aim: Urinary tract infection (UTI) is a common infection in neonates and can presents with unexplained neonatal jaundice and hyperbilirubinemia. We aimed to assess the significance of such symptoms in neonates with UTI.

Materials and Methods: A retrospective study newborn including 102 neonates whose clinical and biological data were collected from medical records. UTI was defined as positive urine culture (any growth in suprapubic aspiration, $>10,000$ by urethral catheterization or $>10,000$ in bag collection of a single organism) associated with pyuria and bacteriuria. Data were analyzed with Stata 12.0.
\end{abstract}

Results: We included 102 neonates with a mean age of $9.5 \pm 6.8$ days (extremes $0-29$ days) and sex ratio of 1.83 . Prevalence of UTI was $36.3 \%$ (respectively $38.9 \%$ of boys and $34.5 \%$ of girls). Jaundice and hyperbilirubinemia were detected respectively in $95.2 \%$ and $53.3 \%$ of newborns with and without UTI, p <0.01). The two most common pathogens were Escherichia coli $(40.0 \%)$ and Klebsiella pneumonia (18\%). After multivariate logistic regression, hyperbilirubinemia $(\mathrm{OR}=13.61 ; 95 \% \mathrm{CI}=2.73-67.81)$ and increased serum creatinine (OR=1.31; 95\% $\mathrm{CI}=1.04-2.76)$ were the risk factors significantly associated with UTI.

Conclusion: These results demonstrated a strong association between jaundice and UTI independently of age, gender, and birth weight. Screening for UTI should be a part of the routine diagnostic workup of neonates with unexplained jaundice.

\section{Introduction}

Urinary tract infection (UTI) is a widespread infection in neonates and can presents with unexplained neonatal jaundice and hyperbilirubinemia [1]. About $60 \%$ to $80 \%$ of preterm newborns present a transient hyperbilirubinemia during the first week of life but few have a pathological underlying condition [2,3]. Nevertheless, in some cases, jaundice may reveal severe neonatal disease like urinary tract infection (UTI). The higher susceptibility of newborns to UTI is linked to risk factors such as secretory IgA level and lower uroepithelial bactericidal activity reduced renal acidification and violent colonization around the urethral during the neonatal period [4].

However, diagnosis of UTI can sometimes be challenging in newborns particularly if laboratory tests are not routinely performed [1,4]. Furthermore, due to multiple possible causes of jaundice in the neonatal period, it is important to have a good clinical orientation to guide diagnosis explorations. This study aimed to assess jaundice among newborns and its importance in the diagnosis of UTI. 


\section{Materials and Methods}

\section{Patients}

This study was carried in neonatal intensive care unit (NICU) at University hospital between 2018 and 2020. All newborns receive during the study period and diagnosed with UTI were included. Data were collected from medical records. Demographic features such as gestational age, birth weight, gender, and age of presentation were included. Clinical findings of UTI were reached from registration files and laboratory tests were performed as hemogram, C-reactive protein, total and direct bilirubin, serum creatinine, urinalysis, and urine culture. Deliveries with intrapartum and postpartum complications, $\mathrm{ABO}$ and/or Rh hemolytic disease, cyanotic babies, extended jaundice, neonatal sepsis, direct hyperbilirubinemia, skin disease, and babies who with a history of previous phototherapy or exchange transfusion were excluded from the study.

Hyperbilirubinemia was defined as, nomogram of phototherapy limits and gestational week, postnatal age, total bilirubin level (mg/ $\mathrm{dL}$ ) and additional risk factors were considered according to the American Pediatric Academia and Turkish Neonatology Committee, Newborn Jaundice Guide. UTI was defined as positive urine culture (any growth in suprapubic aspiration, $>10,000$ by urethral catheterization or $>10,000$ in bag collection of a single organism) related with pyuria and bacteriuria. Pyuria consulted to $>5$ white blood cells (WBC)/hpf of centrifuged urine and bacteriuria to at least 1 bacteria/hpf in an unspun urine sample.

Ampicillin and aminoglycosides were administered to the patients as the empiric treatment, assigned according to the antibiotic sensitivity tests. This study was performed in the newborn units of Tekirdağ Namık Kemal University, between July-
2018 and May-2020. The study was approved by the local ethics committee (No.: 2020.94.04.18)

\section{Statistical analysis}

Data were analyzed by STATA version 12.0 using independent $t$ test for comparing quantitative variables and chi-square test for comparing qualitative variables. Factors associated with UTI were identified using a logistic regression analysis. All statistical tests were considered significant if $\mathrm{p}$ value $\leq 0.05$.

\section{Results}

We included 102 neonates with a mean age of $9.5 \pm 6.8$ days (extremes 0 - 29 days) and sex ratio of 1.83. UTI was diagnosed in $36.3 \%$ of them (respectively $38.9 \%$ of boys and $34.5 \%$ of girls). Jaundice and hyperbilirubinemia were detected in $67.5 \%$ of them (respectively $95.2 \%$ and $53.3 \%$ in newborns with and without UTI, p <0.01). Dosage of inflammation markers showed increased leukocytosis and CRP respectively in $37.5 \%$ and $33.6 \%$ of newborns (Table 1).

Urine culture isolated Escherichia coli (40\%), Klebsiella pneumoniae (18\%), Enterobacter cloacae (12\%) as the most common organisms (Figure 1). One patient had Candida albicans associated with Klebsiella pneumoniae as cause of UTI. Although one patient had a positive hemoculture with Staphylococcus epidermidis, concomitant bacteremia with the same organism was not found in any of the cases. Newborns with UTI tended to be more frequently delivered by $\mathrm{C}$-section, were more aged and had a higher urine specific gravity and serum creatinine. However, birth weight, gestational age, inflammation biomarkers and duration of stay at hospital were not different between the two groups (Table 2).

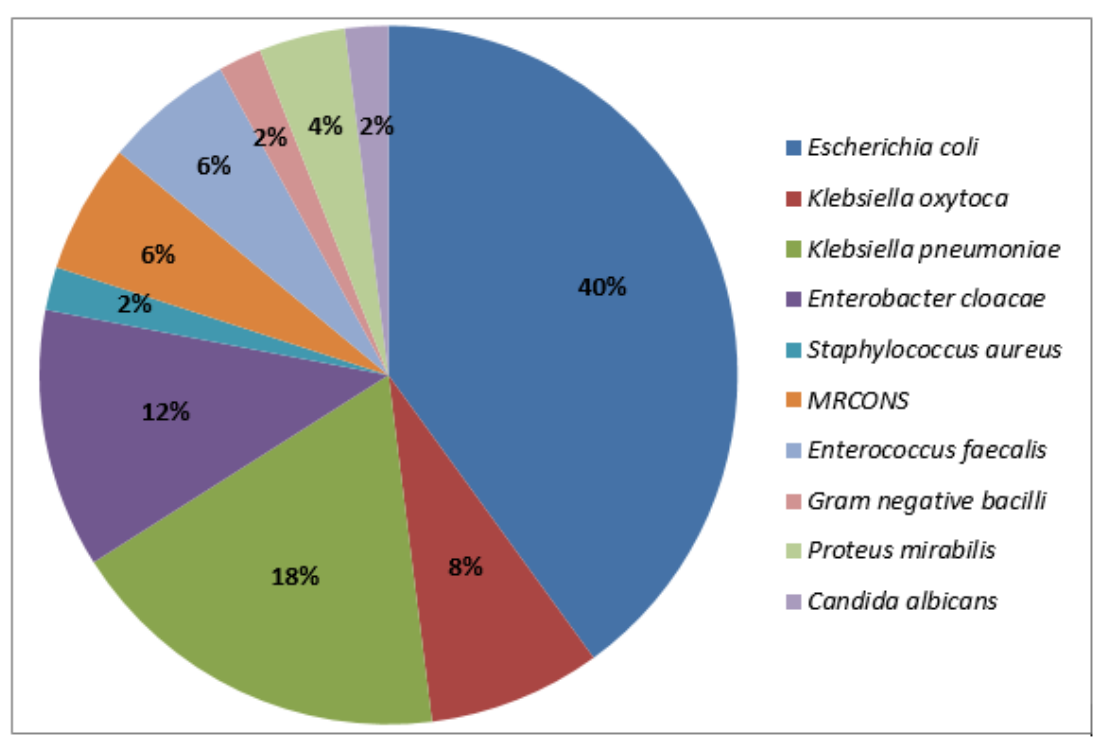

Figure 1: Germs of UTI isolated by urine culture. 
Table 1: Baseline characteristics of newborns included into the study.

\begin{tabular}{|c|c|c|}
\hline Variables & Number (percent) & Mean \pm SD (extremes) \\
\hline Age at admission (days) & & $9.5 \pm 6.8(1-29)$ \\
\hline \multicolumn{3}{|c|}{ Gender } \\
\hline Male & $66(64.7 \%)$ & \\
\hline Female & $36(35.3 \%)$ & \\
\hline Gestational age (weeks) & & $38.31 \pm 1.47(35-41)$ \\
\hline Birth weight (g) & & $3218.0 \pm 482.7(1750-4270)$ \\
\hline \multicolumn{3}{|c|}{ Delivery method } \\
\hline Natural & $36(35.3 \%)$ & \\
\hline C/Section & $66(64.7 \%)$ & \\
\hline \multicolumn{3}{|c|}{ Urine SG } \\
\hline Normal & $91(89.2 \%)$ & \\
\hline Elevated & $11(10.8 \%)$ & \\
\hline \multicolumn{3}{|c|}{ Newborn's blood group } \\
\hline $\mathrm{AA}(+)$ & 37 (38.5\%) & \\
\hline AA $(-)$ & $06(06.2 \%)$ & \\
\hline $\mathrm{AB}(+)$ & $07(07.3 \%)$ & \\
\hline $\mathrm{AB}(-)$ & $01(01.1 \%)$ & \\
\hline $\mathrm{BB}(+)$ & $18(18.7 \%)$ & \\
\hline BB $(-)$ & $01(01.1 \%)$ & \\
\hline $00(+)$ & $23(24.0 \%)$ & \\
\hline $00(-)$ & $03(03.1 \%)$ & \\
\hline Hospitalization duration (days) & & $5.5 \pm 5.47(0-30)$ \\
\hline Leucocytes $\left(\mathrm{mm}^{-3}\right)$ & & $11183.0 \pm 4434.1(12.2-30000)$ \\
\hline Platelets $\left(\mathrm{mm}^{-3}\right)$ & & $349137.3 \pm 134868.8(134000-1013000)$ \\
\hline C-reactive protein (mg/l) & & $08.2 \pm 21.5(0.01-180)$ \\
\hline Total bilirubin (mg/dl) & & $12.9 \pm 6.0(0.61-25.3)$ \\
\hline Direct bilirubin (mg/dl) & & $0.56 \pm 0.2(0.06-1.10)$ \\
\hline Indirect bilirubin (mg/dl) & & $12.3 \pm 5.9(0.52-22.14)$ \\
\hline Serum Creatinine (mg/dl) & & $0.56 \pm 0.2(0.17-1.04)$ \\
\hline
\end{tabular}

Table 2: Clinical and biological parameters in patients with and without urinary tract infection.

\begin{tabular}{|c|c|c|c|}
\hline \multirow{2}{*}{ Variables } & With UTI & Without UTI \\
\cline { 2 - 4 } & Mean \pm SD & Mean \pm SD \\
\cline { 2 - 4 } & Number (percent) & $7.5 \pm 6.8$ & 0.02 \\
\hline Age at admission (days) & $10.7 \pm 7.5$ & $43(66.1 \%)$ \\
\hline Gender & & $22(33.9 \%)$ \\
\hline Male & $23(62.2 \%)$ & & 0.86 \\
\hline Female & $14(37.8 \%)$ & $18(48.6 \%)$ \\
\hline Delivery method & & $19(51.4 \%)$ \\
\hline Natural & $18(27.7 \%)$ & 0.03 \\
\hline C/Section & $47(72.3 \%)$ & \\
\hline
\end{tabular}




\begin{tabular}{|c|c|c|c|}
\hline Urine SG & & & 0.01 \\
\hline Normal & $01(12.5 \%)$ & $37(90.2 \%)$ & \\
\hline Elevated & 07 (87.5\%) & $04(09.8 \%)$ & \\
\hline Newborn's blood group & & & 0.04 \\
\hline $\mathrm{AA}(+)$ & $13(35.1 \%)$ & $24(38.7 \%)$ & \\
\hline AA $(-)$ & $01(02.7 \%)$ & $05(08.5 \%)$ & \\
\hline $\mathrm{AB}(+)$ & $01(02.7 \%)$ & $06(10.2 \%)$ & \\
\hline $\mathrm{AB}(-)$ & $00(00.0 \%)$ & $01(02.7 \%)$ & \\
\hline $\mathrm{BB}(+)$ & $13(35.1 \%)$ & $05(08.5 \%)$ & \\
\hline BB (-) & $00(00.0 \%)$ & $01(01.7 \%)$ & \\
\hline $00(+)$ & $09(24.3 \%)$ & $14(23.7 \%)$ & \\
\hline $00(-)$ & $00(00.0 \%)$ & $03(05.1 \%)$ & \\
\hline Gestational age (weeks) & $38.2 \pm 1.4$ & $38.5 \pm 1.5$ & 0.24 \\
\hline Birth weight (g) & $3157.6 \pm 508.2$ & $3324.0 \pm 419.8$ & 0.09 \\
\hline Hospital duration (days) & $6.45 \pm 04.67$ & $05.0 \pm 5.85$ & 0.19 \\
\hline Leucocytes (mm-3) & $11443.9 \pm 4548.6$ & $10724.6 \pm 4247.3$ & 0.43 \\
\hline Platelets (mm-3) & $333216 \pm 105575$ & $358200 \pm 149015$ & 0.37 \\
\hline C-reactive protein (mg/l) & $11.43 \pm 32.40$ & $06.33 \pm 11.32$ & 0.25 \\
\hline Total bilirubin (mg/dl) & $17.54 \pm 3.68$ & $10.23 \pm 05.50$ & $<0.01$ \\
\hline Direct bilirubin (mg/dl) & $0.70 \pm 0.19$ & $0.48 \pm 0.16$ & $<0.01$ \\
\hline Indirect bilirubin $(\mathrm{mg} / \mathrm{dl})$ & $16.82 \pm 0.59$ & $09.78 \pm 0.66$ & $<0.01$ \\
\hline Serum creatinine $(\mathrm{mg} / \mathrm{dl})$ & $0.49 \pm 0.18$ & $0.66 \pm 0.16$ & $<0.01$ \\
\hline
\end{tabular}

Table 3: Multivariate analysis of factors associated with urinary tract infection.

\begin{tabular}{|c|c|c|c|}
\hline Variables & OR & [95\% CI] & $0.92-1.15$ \\
\hline Age (years) & 1.02 & $2.73-67.81$ & $<.63$ \\
\hline Hyperbilirubinemia $(\geq 1.0 \mathrm{mg} / \mathrm{dl})$ & 13.61 & $1.04-2.76$ & $<0.01$ \\
\hline Serum creatinine $(\mathrm{mg} / \mathrm{dl})$ & 1.31 & $0.14-6.43$ & 0.01 \\
\hline Coombs test & 0.65 & $0.30-4.62$ & 0.75 \\
\hline Delivery method (C-section) & 1.12 & $0.76-2.41$ & 0.27 \\
\hline Low birth weight (<2500g) & 1.05 & $0.13-4.00$ & 0.7 \\
\hline Gestational age (weeks) & 0.71 & & \\
\hline
\end{tabular}

After multivariate logistic regression, only hyperbilirubinemia $(\mathrm{OR}=13.61 ; 95 \% \mathrm{CI}=2.73-67.81)$ and increased serum creatinine $(\mathrm{OR}=1.31 ; 95 \% \mathrm{CI}=1.04-2.76)$ were significantly associated with UTI (Table 3). Age, low birth weight, prematurity and presence of a positive Coombs test did not show significant association with UTI. No underlying urological abnormality was found in newborns and no septic shock was noticed. Prognosis was favorable in all patients who were discharged after treatment with antibiotics adapted to bacterial sensitivity tests. Any case of recurrence of UTI was not observed after hospital discharge.

\section{Discussion}

Jaundice is one of the most common symptoms of UTIs in neonates and may be its sole sign in some cases [4,5]. Many pathophysiological mechanisms could explain UTI related jaundice including hemolysis, direct invasion of the liver parenchyma by blood-borne or lymph borne microorganisms, indirect hepatocellular injury by circulating endotoxins, non-specific liver injury related to hyperpyrexia, malnutrition, and toxemia. Furthermore, jaundice can lead to UTI by altering bactericidal activity in the sera of jaundiced newborns making them more prone to infections [5].

UTIs are common infections during the neonatal period and some demographical characteristics have been reported as risk factors. The present study did not find any gender difference between newborns with and without UTI conversely to previous studies that reported more UTI in boys compared to girls [6]. In 
fact, boys present a higher incidence of UTI during the first year but after this age, the frequency in girls is 10 times more than in boys $[7,8]$.

This male predominance in neonatal UTI may be explained by many factors such as increased incidence of structural abnormalities, phimosis, periurethral colonization and increased susceptibility to bacterial infections [9-11]. Presence of urological abnormalities and absence of circumcision have been reported as risk factors of UTI in infants, but this was not confirmed by our results [12]. In one study by Singh-Grewal et al. circumcision was associated with a significantly lower risk of UTI among young boys [13].

Also, previous studies showed that UTI is more common in premature newborns compared to term neonates [14]. Even if birth weight and gestational age tended to be lower among newborns with UTI, multivariate analysis did not show a significant association between these factors and UTI in our study. In this study where all newborns were in their first month of life, age was not a discriminant risk factor associated with UTI. E. coli was responsible of $40 \%$ of UTI in our study. Similarly, data from retrospective studies suggest that E. coli infection was more associated with hyperbilirubinemia in newborns [15]. Our results showed that routine urine culture may be justified in jaundiced neonates with leukocytosis, increased serum creatinine and prolonged hyperbilirubinemia.

There are some limitations in our study. First, its retrospective design could be a source of selection bias despite we tried to collect data from all the jaundiced neonates with UTI during the study period. Also, the small sample size does not allow generalization of the results. Finally, suprapubic aspiration that is the best method to collect urine sample was not used in most patients, but we associated urinalysis with urine culture to enhance the reliability of results.

In conclusion, this study showed that jaundice due to hyperbilirubinemia is highly prevalent among neonates with UTI. This association between jaundice and UTI was independent of age, gender, and birth weight. Other common biological abnormalities in newborns with UTI were renal failure and inflammation. E. coli is the most frequent germ isolated by urine culture. Screening for UTI should be a part of the routine diagnostic workup of neonates with unexplained jaundice.

\section{Declaration of Conflicting Interests}

The authors declared no conflicts of interest with respect to the authorship and/or publication of this article.

\section{References}

1. Mutlu M, Cayir Y, Aslan Y (2014) Urinary tract infections in neonates with jaundice in their first two weeks of life. World J Pediatr 10: 164-167.

2. Ozdogan EB, Mutlu M, Camlar SA, Bayramoglu G, Kader S, et al. (2018) Urinary tract infections in neonates with unexplained pathological indirect hyperbilirubinemia: Prevalence and significance. Pediatr Neonatol 59(3): 305-309.

3. Subcommittee on Urinary Tract Infection SCoQI, Management, Roberts KB (2011) Urinary tract infection: clinical practice guideline for the diagnosis and management of the initial UTI in febrile infants and children 2 to 24 months. Pediatrics 128: 595-610.

4. Bensman A DO, Ulinski T (2009) Urinary tract infection. 6 ed: Baltimore: Lippincott Williams \& Wilkins.

5. Cisowska A DT, EkGoska I, Szozda A, Lewczykm E (2007) The bactericidal activity of complement in sera of children with infectious hyperbilirubinemia. Adv Clin Exp Med 25: 277-282.

6. Nickavar A, Khosravi N, Doaei M (2015) Early prediction of urinary tract infection in neonates with hyperbilirubinemia. J Renal Inj Prev 4: 92-95.

7. Lee HC, Fang SB, Yeung CY, Tsai JD (2005) Urinary tract infections in infants: comparison between those with conjugated vs unconjugated hyperbilirubinaemia. Ann Trop Paediatr 25(4): 277-282.

8. Chang SL, Shortliffe LD (2006) Pediatric urinary tract infections. Pediatr Clin North Am 53(3): 379-400.

9. Abourazzak S, Bouharrou A, Hida M (2013) [Jaundice and urinary tract infection in neonates: simple coincidence or real consequence?]. Arch Pediatr 20(9): 974-978.

10. Kanellopoulos TA, Salakos C, Spiliopoulou I, Ellina A, Nikolakopoulou NM, Papanastasiou DA (2006) First urinary tract infection in neonates, infants, and young children: a comparative study. Pediatr Nephrol 21(8): 1131-1137.

11. Hsieh MH, Madden-Fuentes RJ, Roth DR (2009) Urologic diagnoses among infants hospitalized for urinary tract infection. Urology 74: 100103.

12. Ghaemi S, Fesharaki RJ, Kelishadi R (2007) Late onset jaundice and urinary tract infection in neonates. Indian J Pediatr 74(2): 139-141.

13.Singh-Grewal D, Macdessi J, Craig J (2005) Circumcision for the prevention of urinary tract infection in boys: a systematic review of randomised trials and observational studies. Arch Dis Child 90: 853-858.

14. Bilgen H, Ozek E, Unver T, Biyikli N, Alpay H, et al. (2006) Urinary tract infection and hyperbilirubinemia. Turk J Pediatr 48: 51-55.

15. Emody L, Molnar L, Kellermayer M, Paal M, Wadstrom T (1989) Urinary Escherichia coli infection presenting with jaundice. Scand J Infect Dis 21: 579-582. 